NASA Technical Memorandum 100921

AIAA-88-2985

NASA-TM-100921

19880014422

\title{
The Challenges and Opportunities of Supersonic Transport Propulsion Technology
}

William C. Strack

Lewis Research Center

Cleveland, Ohio

and

Shelby J. Morris, Jr.

Langley Research Center

Hampton, Virginia

Prepared for the

24th Joint Propulsion Conference

cosponsored by the AIAA, ASME, SAE, and ASEE

Boston, Massachusetts, July 11-13, 1988

\section{N/Sก}


$\cdot$
$\therefore$ 
William C. Strack"

NASA Lewis Research Center

Cleveland, Ohio 44135

and

Shelby J. Morris, Jr.**

NASA Langley Research Center

Hampton, Virginia 23665-5225

\section{Abstract}

The major challenges confronting the propulsion community for civil supersonic transport applications are identified: high propulsion system efficiency at both supersonic and subsonic cruise conditions, low-cost fuel with adequate thermal stability at high temperatures, low notse cycles and exhaust systems, low emission combustion systems, and low drag installations. Both past progress and future opportunities are discussed in relation to perceived technology shortfalls for an economically successful airplane that satisfies environmental constraints.

\section{Introduction}

Although the Concorde ushered in the supersonic transport (SST) era, it has not been a commercial success for a variety of reasons. Nevertheless, for several years there has been a growing interest in the subject of efficient sustained supersonic crulse technology applied to civil transport aircraft. A second-generation SST is envisioned that flies three times as many passengers nearly twice as far and considerably faster than the Concorde while achieving economic and environmental near-parity with comparable technology subsonic transports (Fig. 1 ). The central issue is the level of technology that must be attained in order to realize this vision.

Two independent NASA sponsored studies, known as the High-Speed Civil Transport (HSCT) studies, are currently in progress that address a broad spectrum of technical, economic, environmental, and related issues. While many issues are still being investigated, others have been partially resolved. For example, cruise speed analyses have narrowed the original Mach 0 to 25 range to the Mach 2 to 5 region - thus excluding hypersonic flight with its attendant hydrogen-fueled scramjet technology requirements. It is also clear that large technology improvements are required in all discipline areas to approach economic viability. In what follows, the propulsion technology gaps are discussed in broad perspective in hopes of highlighting the major issues and perhaps stimulating new ideas or novel solutions.

An overview of the major HSCT technical challenges as viewed by a propulsion analyst is depleted in Fig. 2. The concorde consumes about three times as much fuel per seat-mile as equivalent technology (circa 1976) subsonic long-range airplanes. This is largely responsible for its uncompetitive economics - twice the total operating

\footnotetext{
* Supervisory Aerospace Engineer.

**Aero-Space Technologist; Member, AIAA.
}

cost (TOC) as similar technology subsonic transports and much worse than that relative to contemporary technology aircraft. Very large airframe and propulsive efficiency improvements will be required to alter this situation. In our quest for greater productivity through increased speed, we are also confronted with ever increasing difficulties arising from high ram temperature levels. The challenge is to utilize advanced materials to cope with the high temperatures without incurring excessive weight and cost penalties. In addition, the inability of traditional low-cost fuels to provide adequate thermal stability impedes the pursult of higher speeds. Expensive JP-type fuels reach thermal stability limits at speeds near Mach 4, but low cost Jet $A$ is limited to speeds somewhat greater than Mach 2.

There are also several challenging environmental issues. While the sonic boom problem is airframe driven, the excessive airport noise levels are due to the very high takeoff exhaust velocities associated with supersonic engines. Engine exhaust gas emissions is another environmental issue requiring attention. In the remainder of this report, each of these issues will be discussed in more detail, including a summary of previous progress, current status, and future research requirements. Further information, especlally regarding previous studies, is available in Ref. 1.

\section{Fuel Economy}

Figure 3 summarizes prior progress made in reducing supersonic transport engine thrust speciflc fuel consumption (TSFC). Results are normalized by the cruise TSFC of the 1971 U.S. engine that was first proposed for a U.S. supersonic transport. This afterburning turbojet (GE4) performed relatively well at supersonic cruise conditions. But its subsonic efficiency was very inferior to comparable high bypass ratio subsonic engines. To mitigate this mismatch between a fixed-cycle engine and varying mission requirements, the nation embarked on a 10-year NASA sponsored variable cycle engine (VCE) research program that achieved considerable progress during the 1970 's and early 1980's. Compared to the 1971 GE4 afterburning turbojet, the hypothetical VCE engines defined in 1981 (which assumed technology levels beyond 1981) consumed 10 percent less fuel at supersonic and transonic conditions, and 25 percent less at subsonic speeds - reflecting the cycle changing feature of VCE's. A simultaneous 25 percent reduction in engine weight occurred mainly as a result of improved materials. Nevertheless, these gains are insufficient by themselves to obtain good enough fuel economy to enable competition with subsonic aircraft. The subsonic efficiency of the 1981 VCE engines, for example, is 
still only about one-half that of today's high bypass ratio turbofans.

The primary cause of the Concorde's high fuel consumption is the dramatic fall in airplane $L / D$ at supersonic speeds - on the order of one-half that of subsonic transports. This is only partially offset by the trend towards increasing overall engine efficiency with flight speed as shown in Fig. 4. "Installed cruise efficiency" shown here includes inlet and nozzle losses, but not nacelle drag, and represents design point values. The lowest curve represents currently operational powerplants. The middle curve indicates that significant improvement is possible with today's available technology for both subsonic and supersonic regimes. The top band projects future opportunities based principally on NASA cycle analyses. Several alternative cycle concepts are represented, including very advanced VCE and turbine bypass engines (lower boundary), and radically different concepts such as supersonic throughflow turbofans (upper boundary). These advanced technology concepts potentially extend the peak propulsion efficiency leveis from Mach 2+ to at least Mach 4 . Gains of 40 percent or more over Concorde's Olympus are posstble.

Using a simple criterion such as design point efficiency is insufficlent to properly convey the overall impact of advanced technology. For example, this plot shows a relatively modest 8 percent gain between 1987 technology VCE's and advanced VCE's (lower line of top band). Not shown, but vitally important, are even larger improvements in climb efficiency (due to nonafterburning operation) and engine weight for advanced VCE's. To illustrate the complete improvement potential, Fig. 5 displays an example of a "goal" VCE that represents what payoffs would accrue if revolutionary advances in materials and structures technology are achieved. This particular design was generated by General Electric in their recent NASA-sponsored ROMS study. ${ }^{2}$ It assumes essentially uncooled near stolchiometric engine materials coupled to advanced aerodynamics and structural design technologies. This implies extensive use of nonmetallics and intermetallic materials.

Two levels of technology are quoted here: (i) the uncooled stoichiometric goal level is denoted by the right-hand values (GE ROMS), and (2) a $600^{\circ} \mathrm{F}$ cooler level is denoted by the lefthand values (NASA estimate). One-third of the 32 percent ultimate fuel reduction potential is due to a 45 percent engine weight reduction relative to a hypothetical 1984 technology readiness baseline engine. While achieving uncooled stolchiometric technology is certainly a very long-term goal, the magnitude of the payoff is so large that pursuit of high temperature, minimally cooled cores and advanced VCE components is key to substantial improvement in supersonic flight efficiency.

To obtain even better powerplant performance than afforded by applying advanced technology to the VCE, novel high risk concepts will be required. One potential HSCT breakthrough is the supersonic fan concept (Fig. 6). Instead of using a long and heavy inlet system to decelerate the intake airflow to subsonic speeds required by conventional turbomachinery, the supersonic fan efficiently processes air at supersonic throughflow velocities. The advantages include much lower inlet system weight, lighter fan (less stages required for a given pressure ratio), less inlet cowl and boundary layer bleed drag, better inlet pressure recovery, and better matching of bypass ratio variations to flight speed. Of course, there are many unknowns and challenges. What are such a fan's low-speed operating characteristics? How can the core inlet losses associated with unsteady, swirling, supersonic inflow be controlled - or is an aft fan configuration a better solution? Little effort has been expended on this concept to date, although NASA has initiated two concept feasibility research efforts, including an initial fan model test at NASA Lewis Research Center.

The potential payoff of supersonic throughflow fan (SSTF) technology for a typical SST application has been analyzed by NASA. ${ }^{3}$ One of the major contributors is the inlet size and weight reduction to about one-half that of a conventional supersonic inlet. This also reduces the inlet bleed drag penalty about 70 percent. The installed efficiency is improved nearly 10 percent relative to a comparable technology conventional turbofan engine, the propulsion system weight is reduced about 25 percent, and together these improvements would yield approximately a 22 percent reduction in mission fuel for a Mach 3, $5500 \mathrm{~nm} \mathrm{HSCT}$ (Fig. 7).

Figure 8 displays the impact of potential future technology advances on airplane fuel consumption - recognizing that the key to viable HSCT economics is mission fuel cost levels approaching those for future subsonic airplanes. Achleving 100 percent fuel usage parity with the subsonic competition is not necessary because of the increased productivity assoclated with the much higher speed HSCT's. However, it is important to at least be in the same neighborhood. which the Concorde and previous SST study airplanes cannot achieve despite their relatively short range capabllities. Even a current technology $4500 \mathrm{~nm} \mathrm{HSCT}$ falls far short of achieving fuel-parity. Incorporating advanced propulsion technology with a $3500^{\circ} \mathrm{F}$ level core coupled to a supersonic throughflow fan yields a major gain towards fuel-parlty in the Mach 2 to 3 region even if the design range is increased from 4500 to $5500 \mathrm{~nm}$. To achieve true fuel-parity and 6500-nm range would al so require substantial airframe improvements - on the order of 20 percent $L / D$ improvement and 25 percent structural weight reduction. These are preliminary first order results subject to modifications as the on-going studies evolve (e.g., the results in Fig. 8 do not properly recognize an airport noise constraint). Another uncertainty is the possible introduction of a very advanced all-new subsonic airplane. An estimate of that possibility is included here that has an 11 percent L/O improvement, a 15 percent structural weight improvement, and a 33 percent propulsion efficiency improvement. The conclusion to be drawn from this analysis is that the large HSCT fuel consumption impediment can be overcome, but it will require very large technology gains in all disciplines - propulsion, airplane aerodynamics, and airframe structures.

\section{Mixed Compression Supersonic Inlets}

Achieving supersonic flight at moderate Mach 2 Concorde speeds can be viewed as relatively straightforward technologically, al though large technology improvements are needed even at Mach 2 
to yield an economically successful alrplane. Pushing the cruise speed substantially higher is certainly desirable, but introduces a series of ever-increasing technological challenges - beyond the fuel economy of just the engine by itself. One of these new challenges is illustrated in Fig. 9. Conventional external compression inlets accomplish all of their diffusion outside of the intake duct through several oblique shocks and a terminal normal shock located at the cowl lip. This type of inlet delivers adequate performance and is wellbehaved (stable) under all transport flight conditions up to about Mach 2. Beyond Mach 2, though, the performance of external compression inlets rapidly deteriorates because of the excessive cowl drag associated with the increasing cowl lip angle and the inability to increase the number of oblique shocks due to excessive inlet length and weight penalties. Flight beyond Mach 2, therefore, requires a mixed compression type inlet that performs some of the diffusion inside the intake duct through more oblique shocks and a normal shock near the throat. This introduces other problems - notably more boundary layer bleed to avoid adverse shock-boundary layer interactions (separation) and inlet shock system instability. The result is a much more complex inlet and control system. Neither transports nor fighters have been flown with such inlets, yet the need for utmost propulsion efficlency will require it for high-speed transports.

Mixed compression inlets are quite susceptible to a phenomena known as inlet instability or "unstart" as illustrated in Fig. 10. Whenever a disturbance that reduces the inlet mass flow occurs, the internal shock system moves abruptly upstream and repositions itself completely outside the intake duct. This causes an abrupt and severe drop in thrust due to lower recovery and mass flow, and a large increase in drag. The precipitating disturbance could be relatively small such as encountering a strong gust or rapidly changing the angle-ofattack. If the initial disturbance is large (e.g., compressor stall), the transient response can be very severe - possibly unstarting neighboring inletengine systems, which would likely throw the airplane into a violent yaw and roll maneuver. To prevent such unacceptable behavior, some form of stability control system is needed.

One inlet stability improvement concept consists of a set of self-actuating bleed valves located in the inlet nacelle (Fig. II). These rapid response rate pneumatic valves will open in response to the increase in duct pressure produced by a transient excursion of the inlet terminal shock forward from its steady-state position. As the shock moves forward it exposes the stablilty bypass plenum to increased pressure and automatically activates the bleed valves which then spill inlet bleed air overboard. This increases the inlet mass flow and forces the shock rearward, and thereby reestablishes stability. The valves close when the transient disturbance subsides and the shock has retreated to its steady state position. 4-5

An experimental wind tunnel test program at NASA Lewis verified the feasibility of this concept during the mid 1970's. A five-fold increase in stabllity margin was demonstrated using a YF-12 system simulation. While encouraging, these initial tests represent just a beginning - not an established data base. Considerable research lies ahead to adequately address this important issue.
Exhaust Nozzle Performance

The exhaust nozzle for an HSCT must perform well at three critical flight conditions - takeoff, subsonic cruise, and supersonic cruise. The experimental model test results shown in $\mathrm{Fig} .12$ (NASA Lewis 8 - by 6-Ft Supersonic Wind Tunnel) of an ejector nozzle show that, while good takeoff and supersonic cruise performance was achieved, the subsonic cruise performance was disappointingly low due to flow separation over the inlet doors of the ejector. This shortfall is important because it significantly increases the reserve fuel allowance required to reach an alternate airport. For longrange HSCT's, the amount of reserve fuel is quite large - equal in magnitude to the payload weight. In addition, it is critical to obtain high nozzle performance at the transonic thrust minus airplane drag "pinch point" to allow adequate aircraft acceleration.

\section{Transonic Propulsion System Drag}

Just as exhaust nozzle performance is critical during subsonic flight, so also is the minimization of transonic installation losses associated with inlets and nozzles. The inlet problem arises from a major mismatch in inlet airflow supply capacity (too much) compared to the engine demand as displayed in $\mathrm{Fig}$. 13. This mismatch causes some of the inlet-processed air to be spilled overboard during off-design conditions. This represents a loss called spillage drag that is proportional to the amount of spilled airflow. The left-hand plot shows that spillage increases rapidly as an afrplane is slowed down from its design cruise speed condition to transonic speeds, and that this penalty becomes worse as design cruise speed increases. Similarly, a supersonic exhaust nozzle is closed down during transonic flight to obtain maximum thrust but this also produces an external flow loss known as boattail drag (Fig. 13). The nozzle boattall transonic drag penalty also rises rapldly with design cruise speed. At high design Mach numbers, the sum of the transonic inlet spillage drag, boattall drag, and nacelle drag could equal or exceed the drag of the airframe. Finding solutions to these installation problems is essential to achieve an acceptable airplane design.

\section{The High-Speed Fuel Issue}

Conventional low-cost Jet $A$ fuel cannot withstand the high temperatures associated with flight speeds much in excess of about Mach 2 . If subjected to temperatures above approximately $250^{\circ} \mathrm{C}$ (time dependent also) they thermally decompose and form coke deposits that clog fuel supply components and fuel injectors. Consequently, a challenge exists to extend the thermal stability of conventional jet fuel to higher temperatures without incurring a significant fuel price increase either in the fuel manufacture or associated with special fuel transportation and handling requirements such as with JP-7 and cryogenics (Fig. 14). While the practical use of hydrogen lies far into the future, liquid methane remains an intriguing possibility due to its current low price and high thermal stability. Endothermic fuels offer more heat sink capacity, but are fraught with offsetting practical and economic penalties. Uncertain future fuel prices and infrastructure costs cloud the issue of fuel selection and, consequently, airplane design speed as well. In the interim, the current HSCT 
studies are proceeding under the assumptions defined in Fig. 15. The dark squares represent the baseline fuel prices while the shaded bands represent the range of prices to be considered in sensitivity analyses. Prices are quoted in terms of equivalent gallons of jet $A$ (EGJA) to account for variations in energy content.

\section{Takeoff Nolse Reduction}

The first generation of hypothetical SST's of the early 1970's used afterburning turbojets and would have provoked the irritation of many people living around major airports. Reducing their high jet exhaust velocities (over $4000 \mathrm{ft} / \mathrm{s}$ ) by oversizing the engines and throttling back during takeoff reduces noise somewhat, but it also increases airplane size too rapidly to be an effective method for more than a few decibels as shown in Fig. 16 . Each curve in Fig. 16 represents various amounts of engine oversizing for a fixed mission. Considerable noise reduction progress evolved during the 1970 's and early 1980's through a combination of variable cycle features and many noise suppression concepts experimentally tested. Unfortunately. even this progress is insufficient to meet current FAR 36 Stage III requirements. The $6-\mathrm{dB}$ noise shortfall shown in Fig. 16 is for a Mach 2.4, $4000 \mathrm{~nm}$ range airplane. If we select even greater speeds and ranges without simultaneous airplane weight reducing technology improvements, then the noise shortfall can become significantly worse as depicted by the sensitivity curves of Flg. 17 .

Much research lies ahead if we are to achieve a quiet HSCT without excessive noise reduction penalties. Some of the noise reduction concepts illustrated in Fig. 18 have been explored in axisymmetric configurations suitable for flight speeds up to Mach 2.5. These concepts need database extensions in both axisymmetric and two-dimensional nozzle configurations. Other concepts have practically no database at all and are quite speculative. For example, the concept of enhancing exhaust jet mixing with pneumatic oscillators represents a very speculative and technically challenging strategy. The remote augmented thrust system concept guarantees low noise with its high mass flow, low pressure ratio fan. But it introduces different problems - notably, how to integrate the deployable remote takeoff fans into the airframe.

\section{Emissions Reduction}

Previous airport pollution concerns precipitated a NASA emissions reduction research program that led to several emission control mechanisms including the development of two-zone combustors. The conventional single-zone combustors have their high power efficiency compromised to obtain good ignition and stability at low engine power levels. The improved two-zone combustors utilized a pilot stage optimized for idle conditions and a main stage optimized for cruise power. This resulted in leaner, well-mixed high-power combustion with approximately one-half as much NOX emissions assuming the engine cycle remains unchanged ( $F i g .19$ ). However, our continued quest for higher overall engine efficlency produces even higher cycle temperatures which increases NOx production. Hence, the final engine designs of the VCE program, if built, would have produced about as much NOX as the decade-earlier technology Concorde engines. Today, we face the same dilemma - performance driven designs will increase NOX while emissions driven designs will reduce performance.

There are several nonexclusive approaches to NOx reduction. Reducing airplane weight obviously reduces emissions through reduced fuel consumption and this may be achieved via airframe aerodynamic and structural efficiency improvements as well as propulsion system improvement. A more direct and effective strategy is to alter the engine cycle parameters, efther by compromising the cycle pressure ratio and/or turbine inlet temperature or by the addition of a heat-pipe combustor precooler (or other heat exchange mechanism) to lower the compressor exit temperature. These approaches are based on an empirical database that relates NOX production rates to an exponential function of combustor inlet temperature and a linear function of combustor outlet temperature. The combustor precooling approach (Fig. 20) is a new idea and analyses are currently underway to assess its merit.

More drastic approaches involve changing the fundamental combustion process. This includes concepts to avoid near-stoichiometric flame temperatures (Fig. 21) and reduced residence times. The lean premixed prevaporized combustor approach avolds large recirculation regions within the primary combustion zone thereby reducing the residence time considerably, but compromising combustor stability and altitude relight reliability while introducing flashback tendencies. The rich burn/ quick quench/lean burn concept appears quite attractive if a homogeneous rich mixture can be achieved in reasonably short lengths. Limited experiments performed for ground-based applications, while encouraging, need to be extended to flight applications. Some of these concepts might be feasible for near-term service while others will require considerable technology effort just to determine their practicality. NOx reductions to approximately $1 / 3$ of current levels seem feasible for the near-term approaches and to $1 / 10$ for the far-term approaches (Fig. 22).

\section{Summary}

As the 21 st century approaches, it is becoming increasingly clear that efficient supersonic cruise flight is within our technological reach albeit a very large reach. Many challenging propulsion problems need to be resolved before a state of technology readiness is achieved (Fig. 23). A very large improvement in propulsion system efficlency is needed both at supersonic crutse and subsonic cruise conditions. Toward that end, several advanced engine concepts are being considered that, together with advanced discipline and component technologies, promise at least 40 percent better efficiency than the concorde engine. The quest for higher productivity through higher speed is also thwarted by the lack of a conventional. low-priced fuel that is thermally stable at the higher temperatures associated with faster flight. Extending Jet $A$ type fuel to higher temperatures and the use of methane are two possibilities requiring further investigation. Airport noise remains a tough challenge because previously researched concepts fall short of achieving FAR 36-III noise levels. Innovative solutions may be necessary to reach acceptably low noise. Similarly, achieving low exhaust emissions will require cycle compromises and unconventional combustor approaches. While the technical challenges are indeed formidable, it is 
reasonable to assume that the current shortfalls in fuel economy and environmental acceptability can be overcome through an aggressive propulsion research program. Achievement of the propulsion goals outlined herein would indeed revolutionize the future world air transportation system.

\section{References}

1. Morris, J.M. Jr., and Strack, W.C., Propulsion System Issues for the High-Speed Civil Transport Study, AIAA Paper 87-2938, Sept. 1987.

2. Feig, P.D., "Revolutionary Opportunities for Materials and Structures Study," NASA CR-179642, 1987.
3. Franciscus, L.C., "The Supersonic Through-Flow Turbofan for High Mach Propulsion," AIAA Paper 87-2050, July 1987. (NASA TM 100114.)

4. Sanders, B.W., and Mitchell, G.A., "Increasing the Stable Operating Range of a Mach 2.5 Inlet, AIAA Paper 70-686, June 1970. (NASA TM $X-52799$.

5. Sanders, B.W., and Mitche11, G.A., "Throat Bypass Bleed Systems for Increasing the Stable Air Flow Range of a Mach 2.50 Axisymmetric Inlet with 40-Percent Internal Contraction," NASA TM X-2779, 1973.
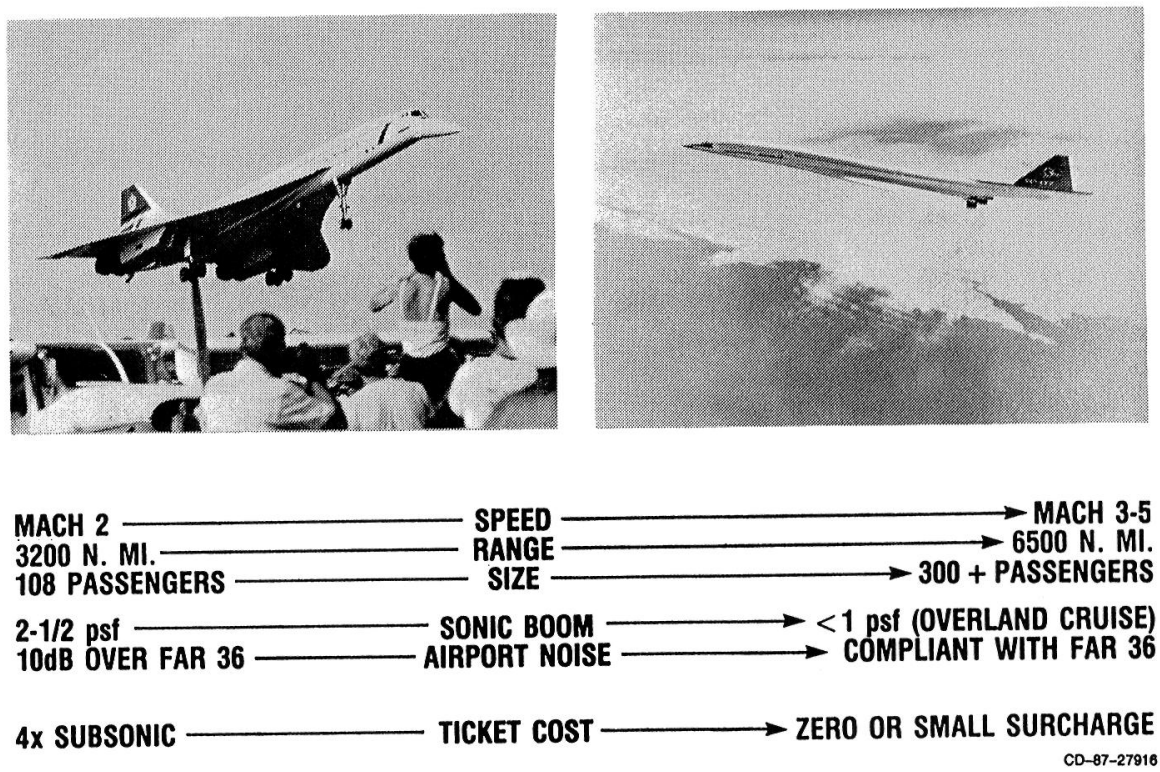

Fig. 1 A vision of future high-speed transport. 


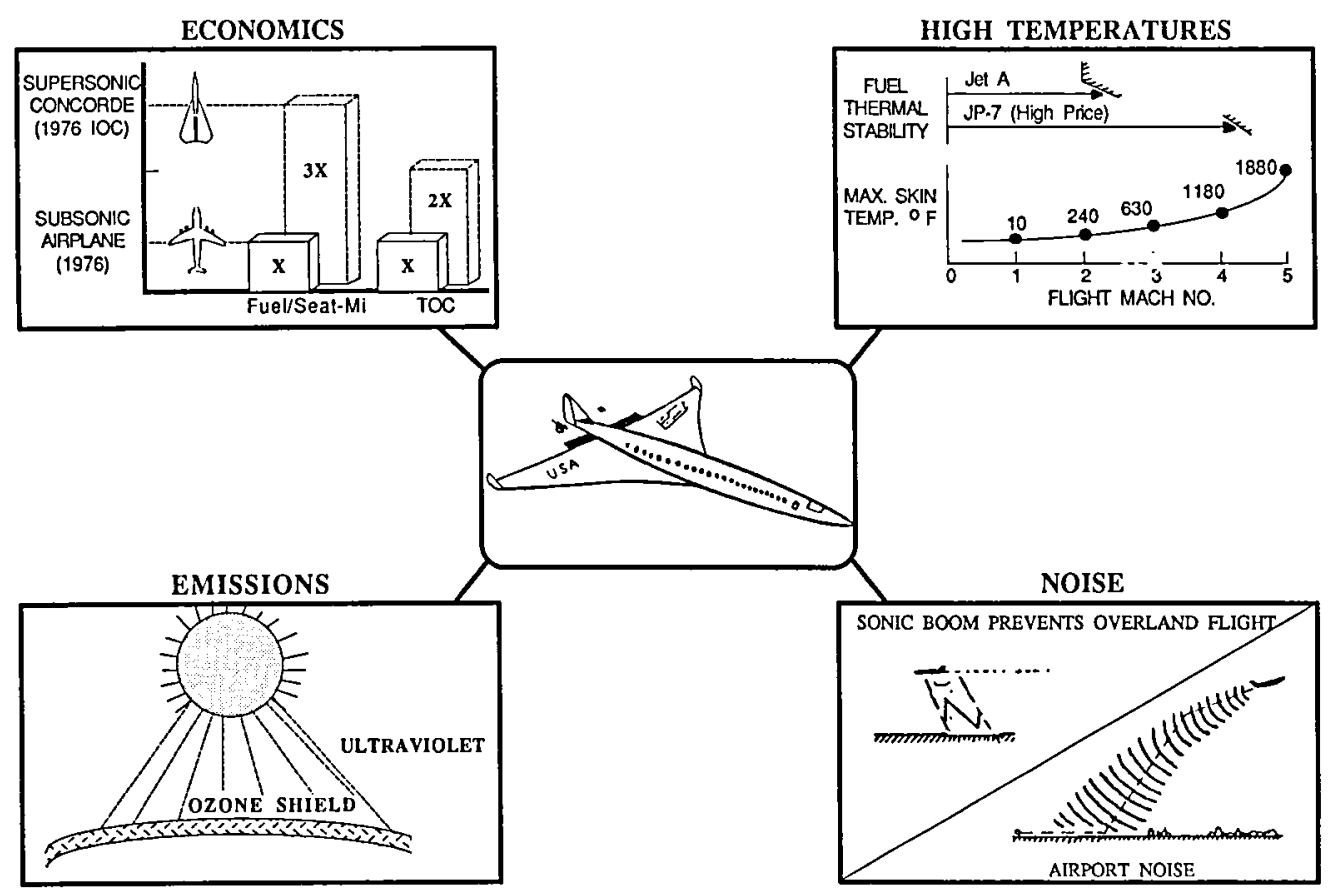

Fig. 2 Challenges to high-speed transports.

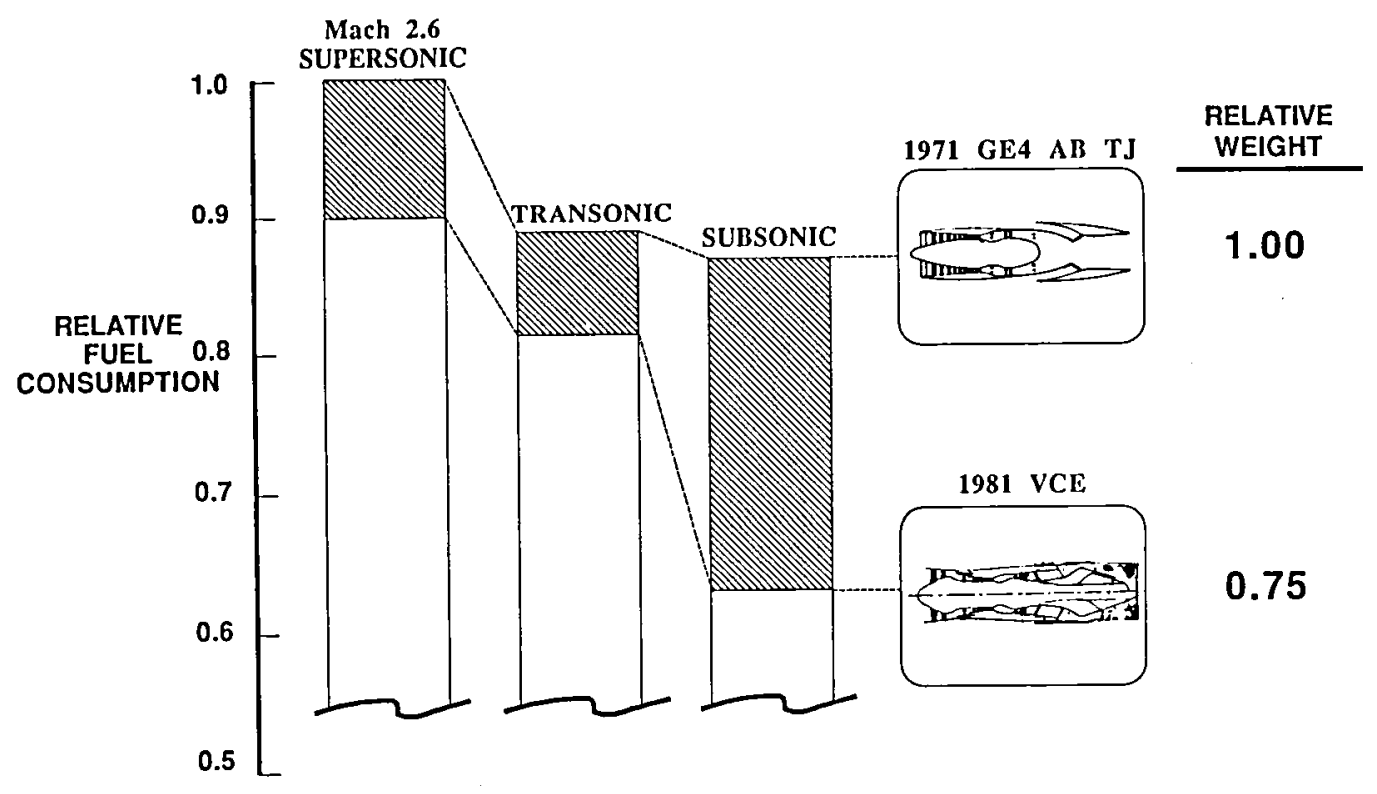

Fig. 3 SST propulsion progress. 


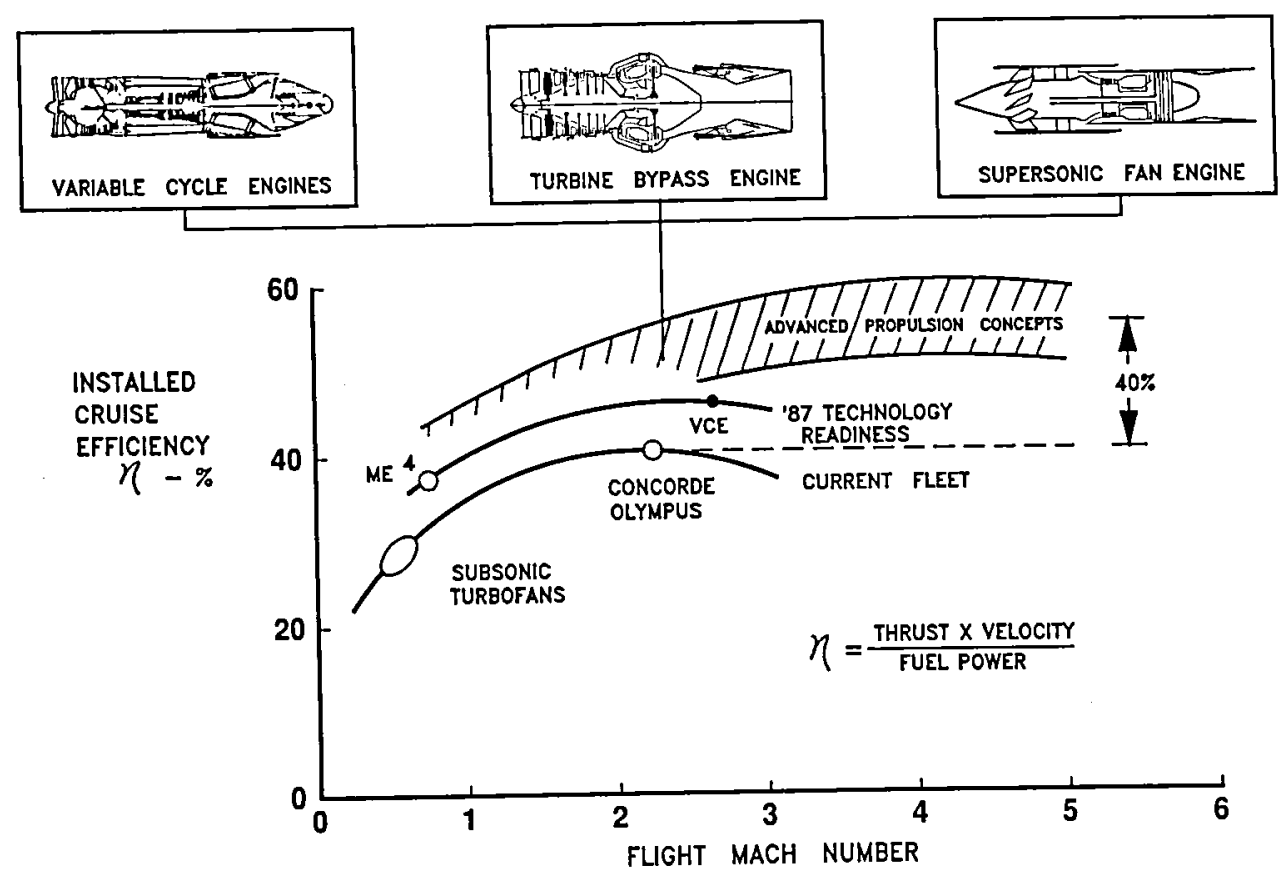

Fig. 4 Future high-speed propulsion performance potential.

\section{POTENTIAL MACH 3 CRUISE CONDITIONS}

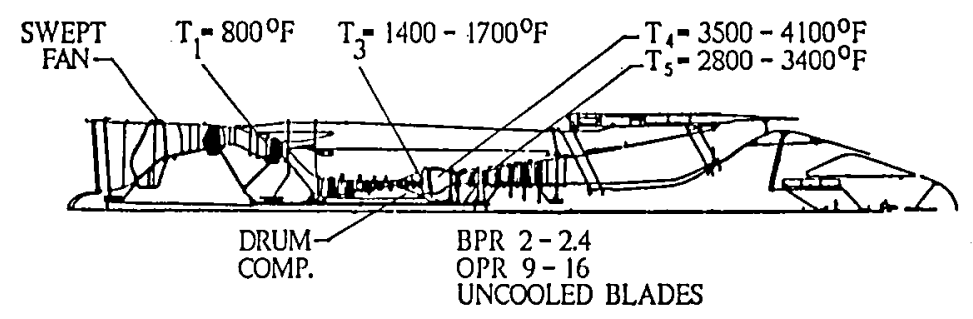

BENEFITS (MATERIALS \& AERO) 290 PAX 5000 NM TRANSPORT

Relative to Current Technology @ \$.60/gal.

FUEL $\quad 27-32 \%$

DOC $13-15 \%$

Fig. 5 Variable cycle engine goal. 


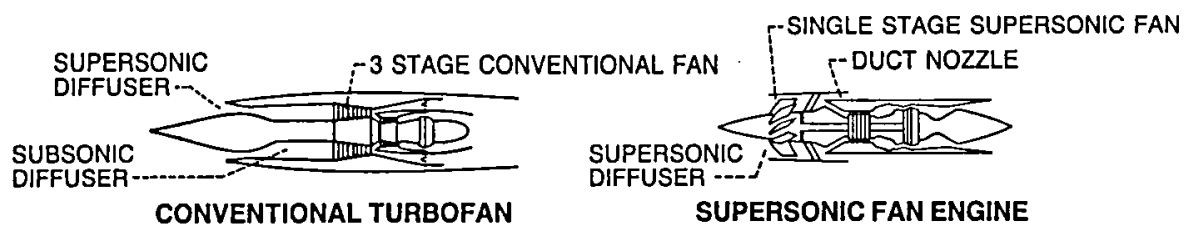

SUPERSONIC FAN ENGINE FEATURES

IMPLICATIONS

- SHORT, ALL SUPERSONIC INLET

- LOWER WeIGHT, LOWER INLET DRAG

- SINGLE STAGE SUPERSONIC FAN

- LOWER WeIGHT AND COST, RUGGed bLADING

- BPR DECREASES WITH MO

- HIGHER CRUISE THRUST

Fig. 6 Supersonic throughflow fan engine.

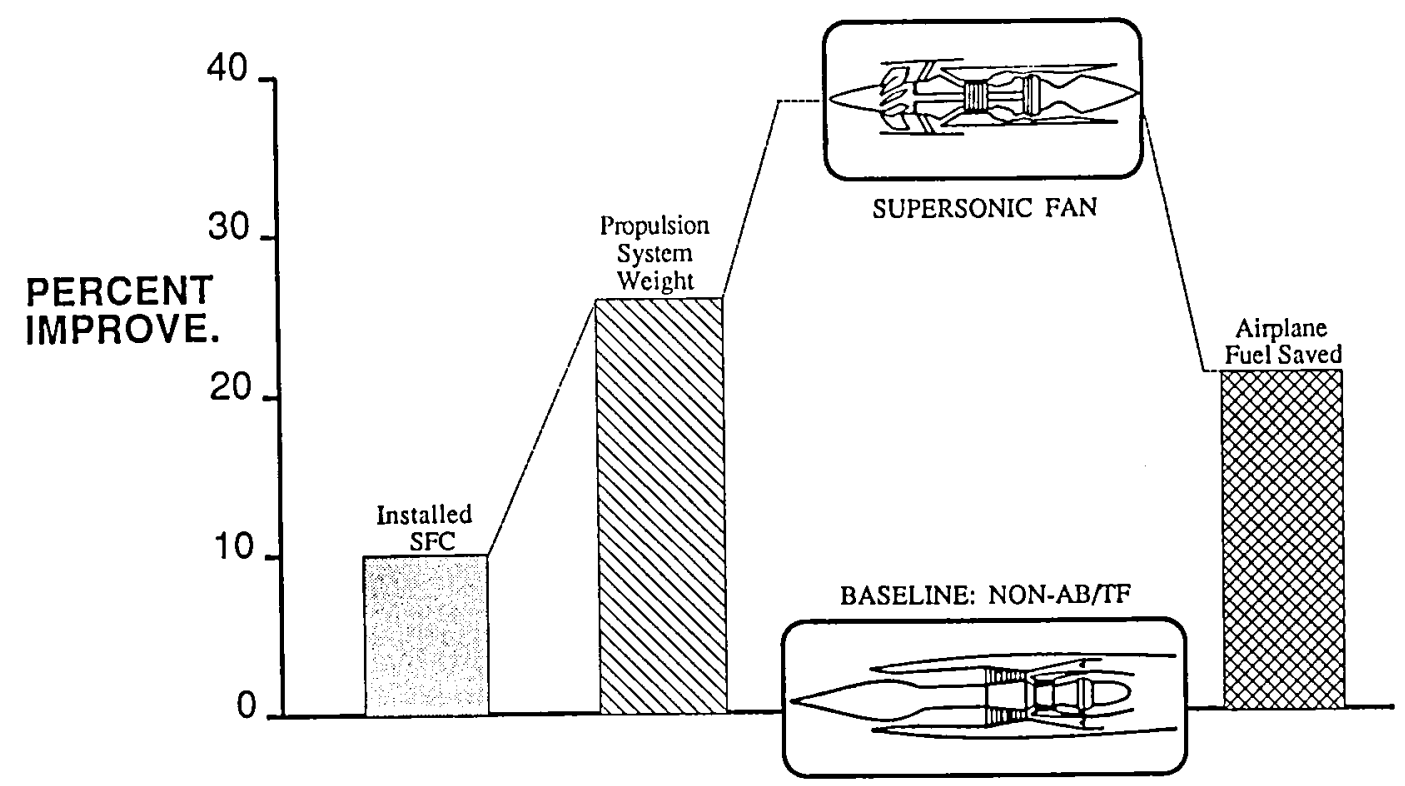

Fig. 7 Benefit of supersonic throughflow fan. Mach 3 commercial transport, 300 passengers, 5500 n.m. range. 


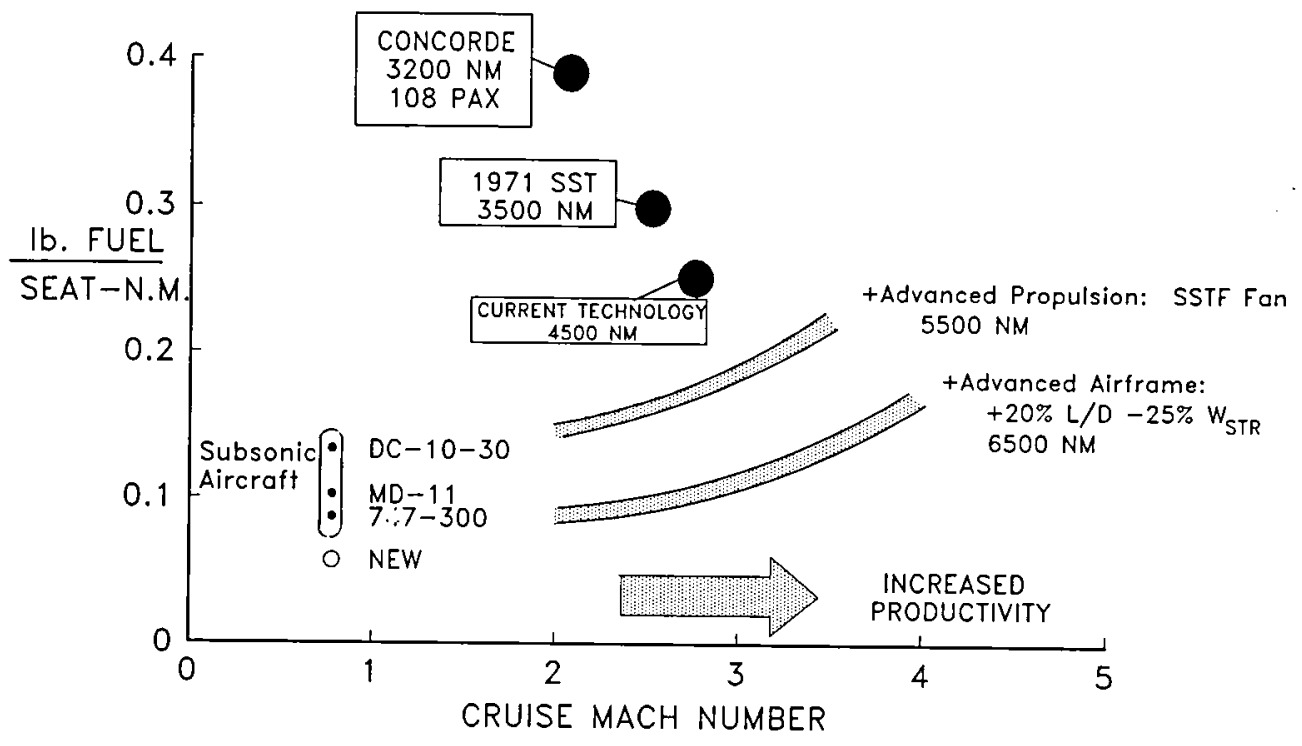

Fig. 8 Impact of technology on fuel economy. 300 passengers, unconstrained noise.

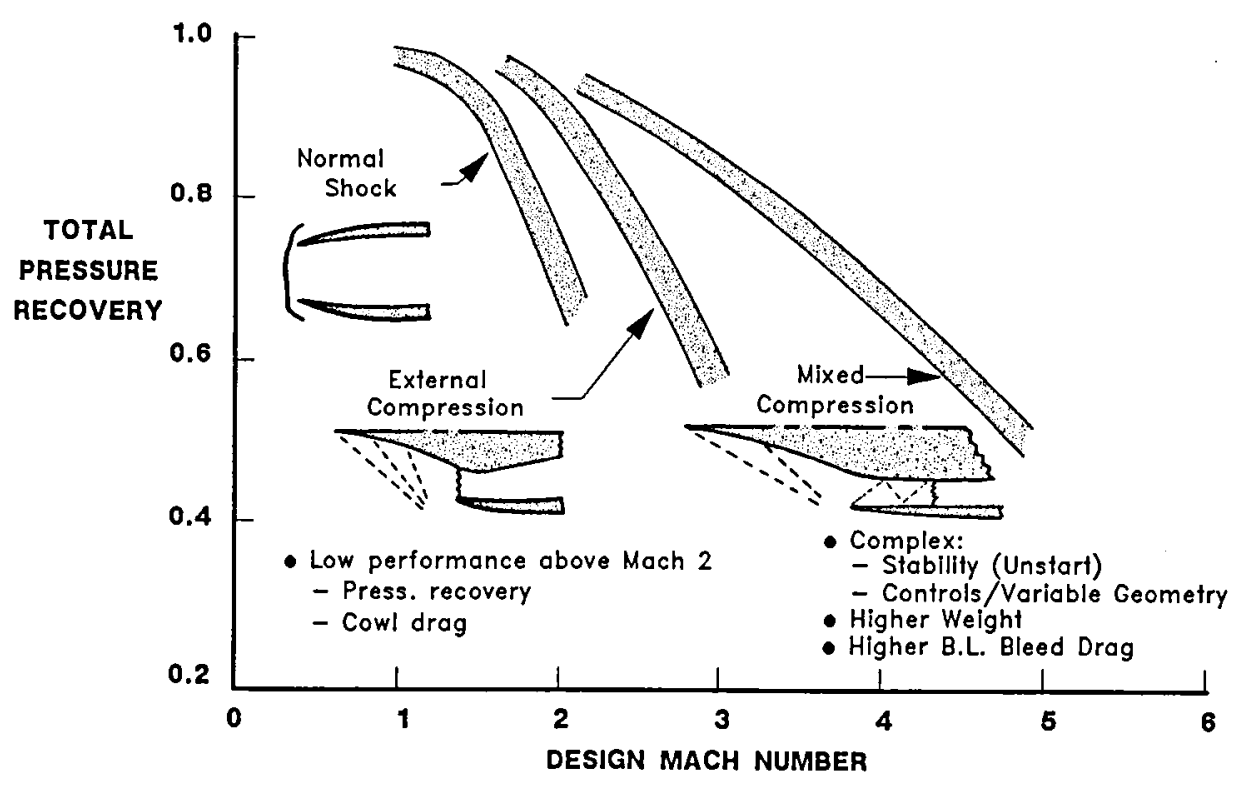

Fig. 9 Supersonic inlet performance. 


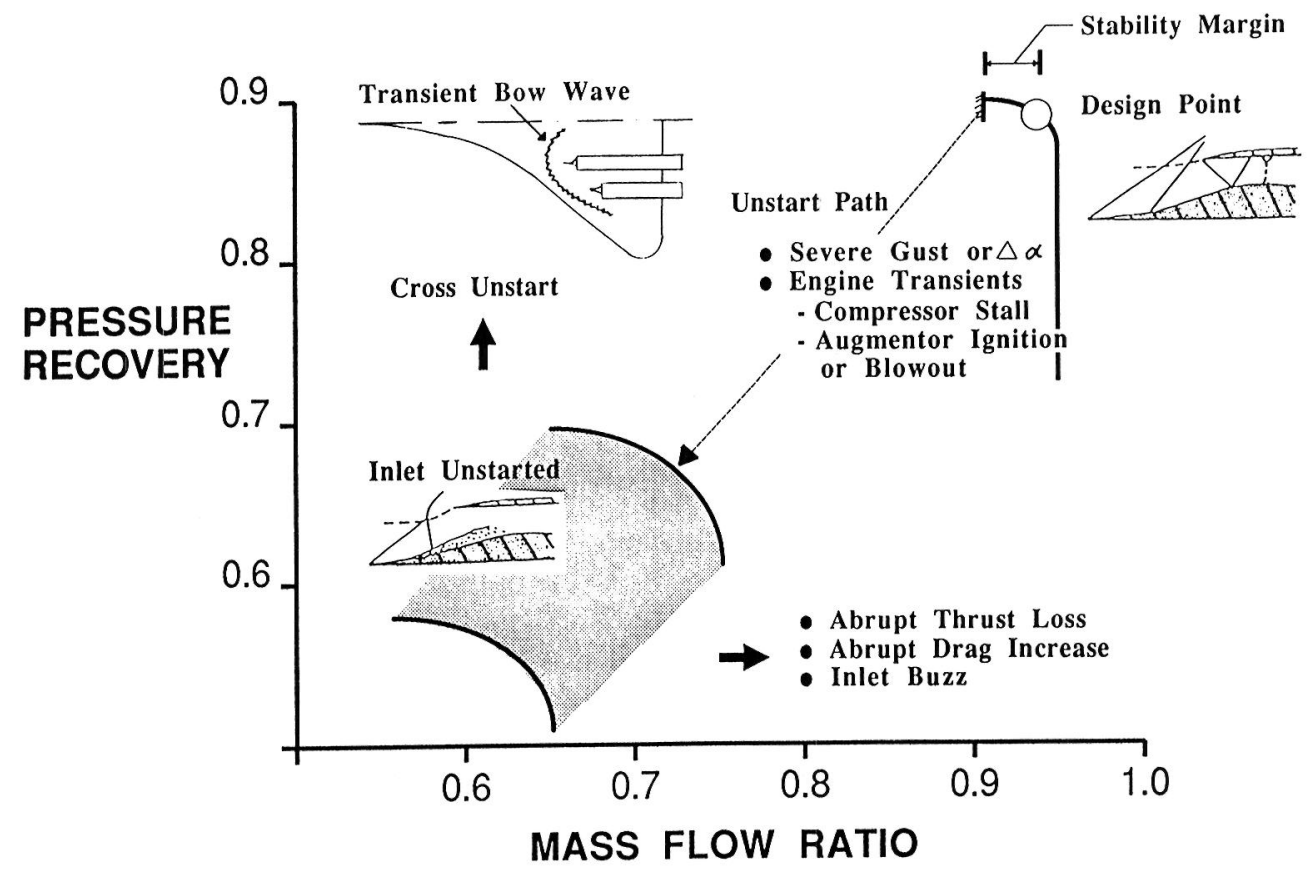

Fig. 10 Mixed compression supersonic inlet instability.

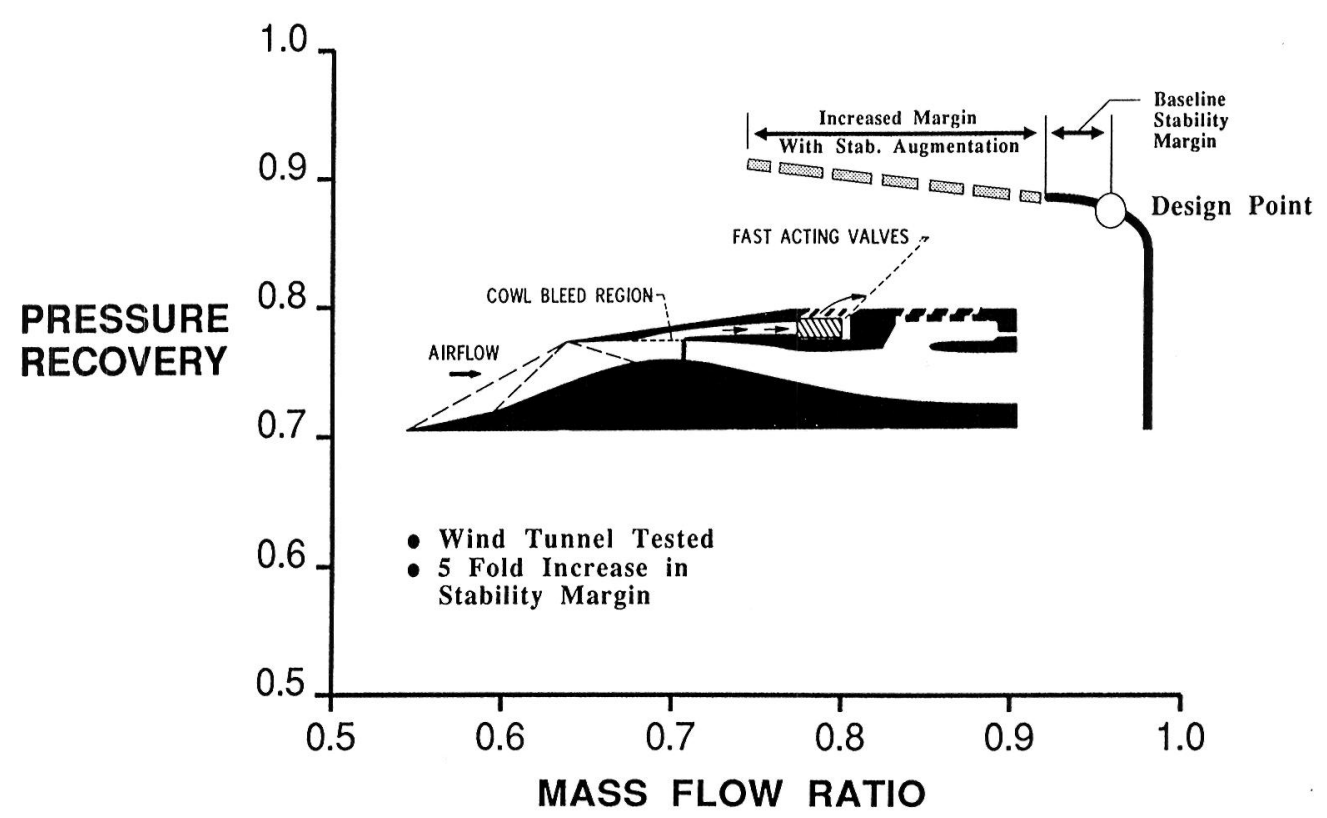

Fig. 11 Mixed compression inlet stability improvement. 


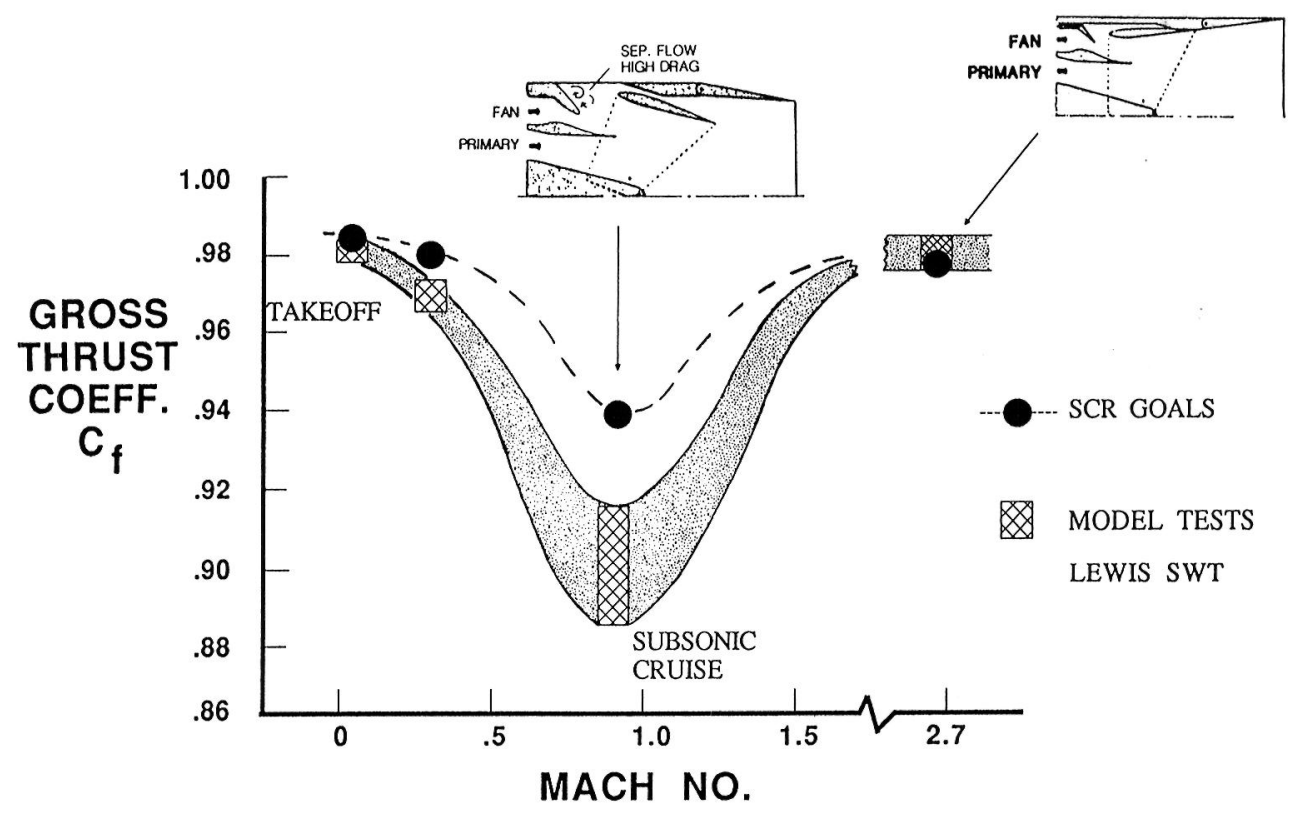

Fig. 12 Supersonic cruise nozzle performance. VCE research ejector.

INLET
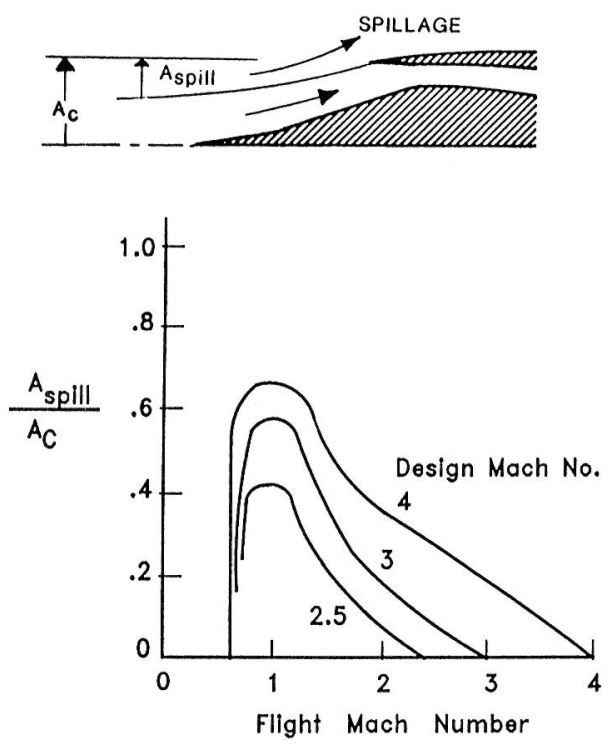

NOZZLE
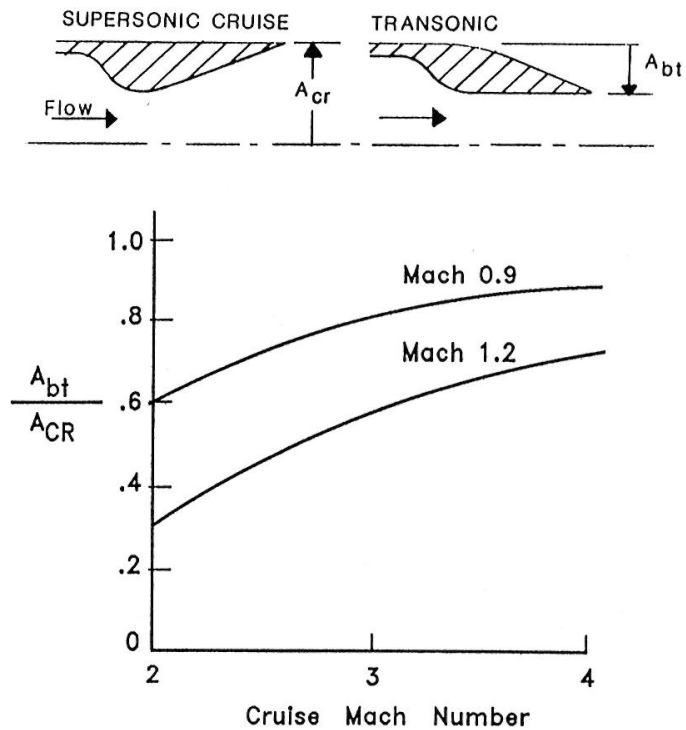

Fig. 13 Transonic propulsion system drag. 


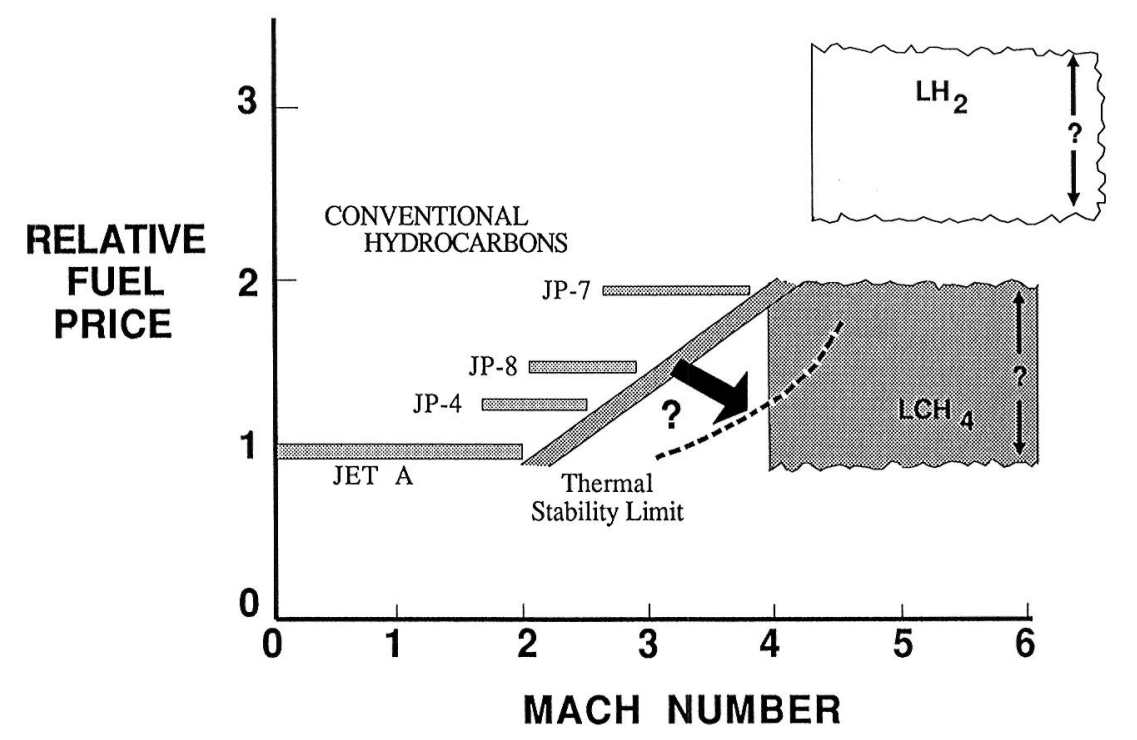

Fig. 14 The high-speed transport fuels issue.

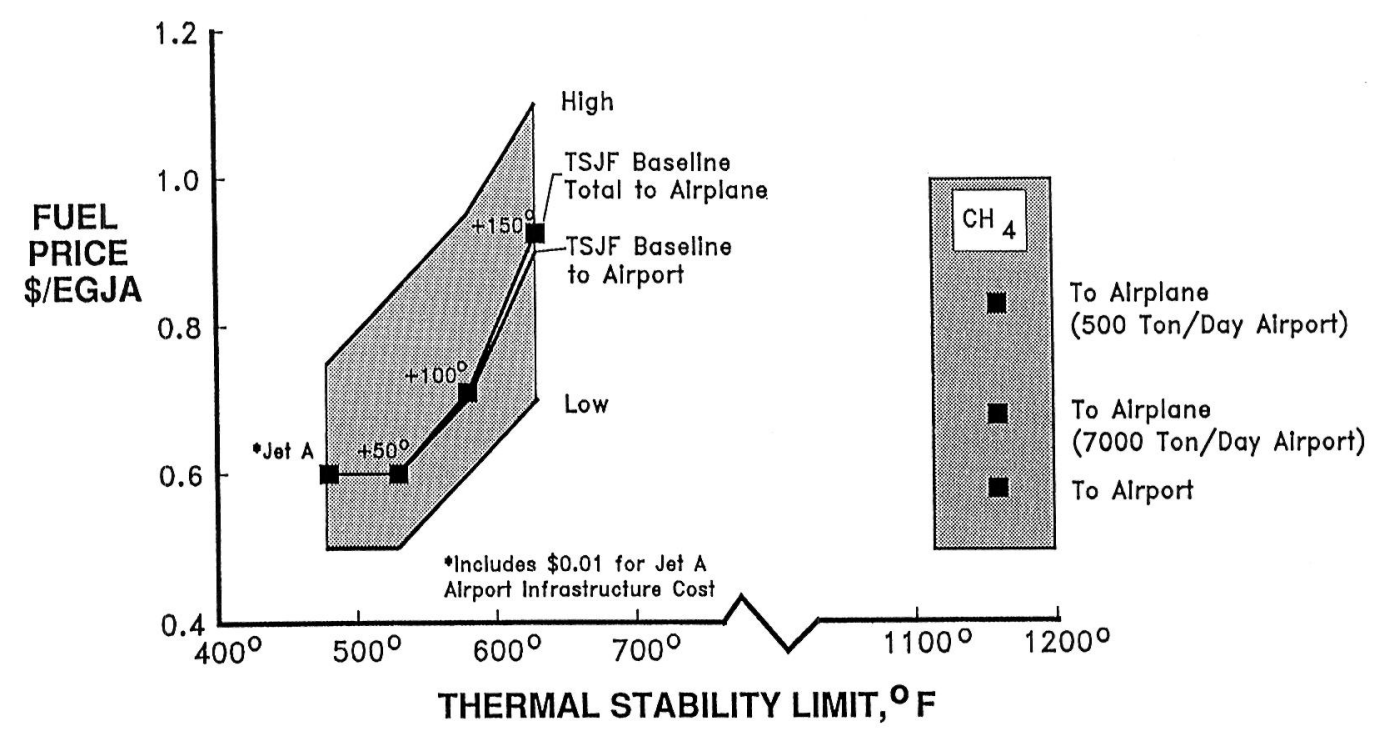

Fig. 15 HSCT studies fuel price assumptions for thermally stable jet fuel (TSJF) and methane $\left(\mathrm{CH}_{4}\right)$. 


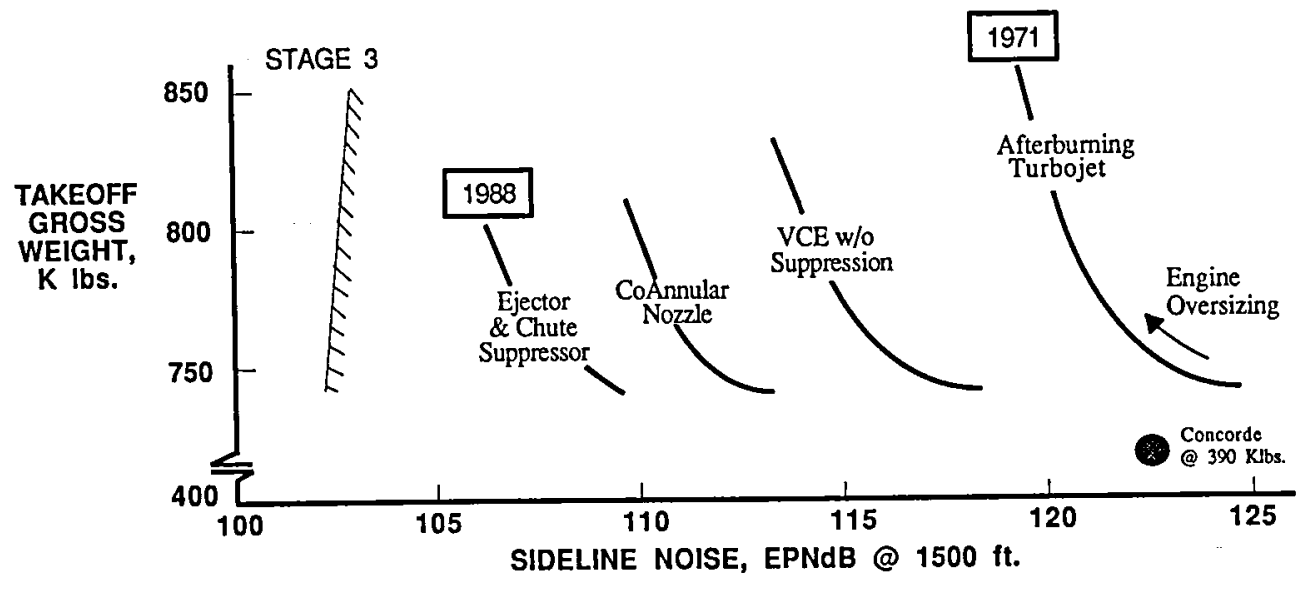

Fig. 16 SST takeoff noise reduction progress. Mach 2.4, 4000 n.m. range, 300 passengers.

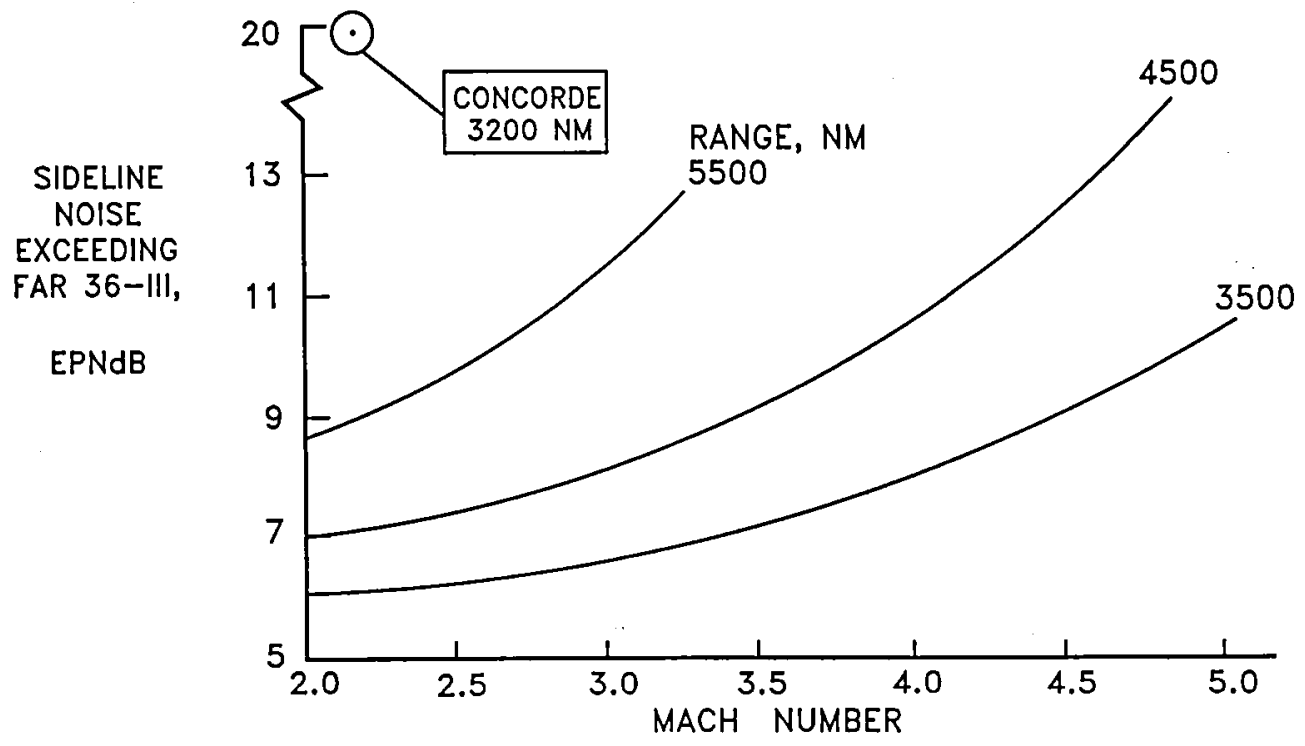

Fig. 17 High-speed civil transport take-off noise challenge. Suppressed VCE turbofan/ramjet engines, constant liftoff velocity, 1988 technology. 


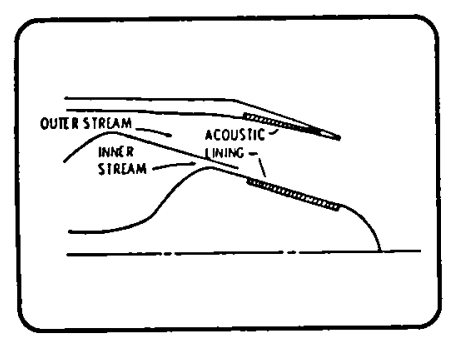

ACOUSTIC LINING

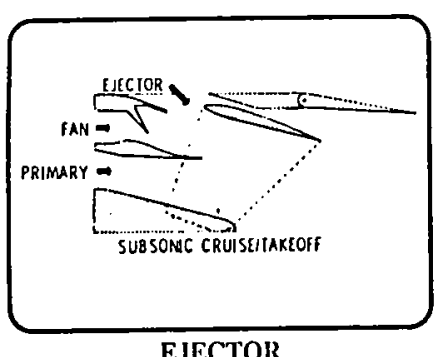

EJECTOR

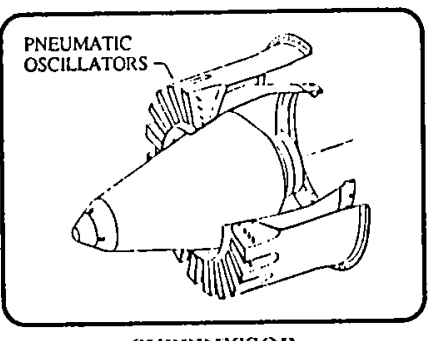

SUPPRESSOR

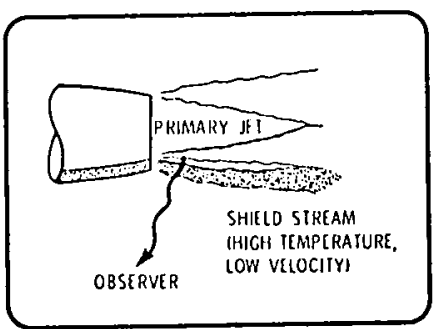

THERMAL ACOUSTIC SHIELD

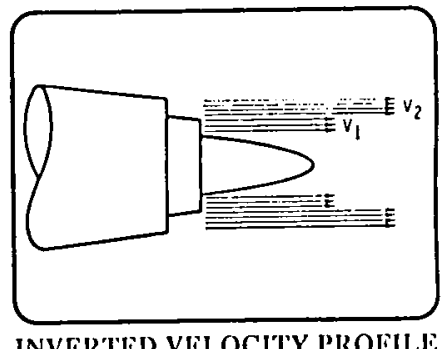

INVER'TED VELOCITYY PROFILE

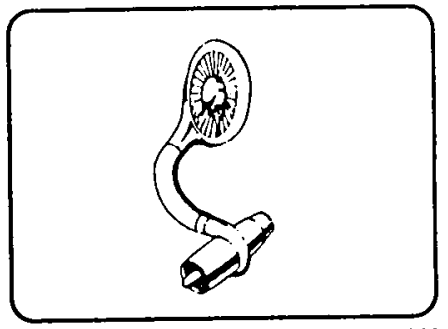

REMOTE AUGMENTED THRUSI SYSTEM

Fig. 18 Jet noise reduction concepts.

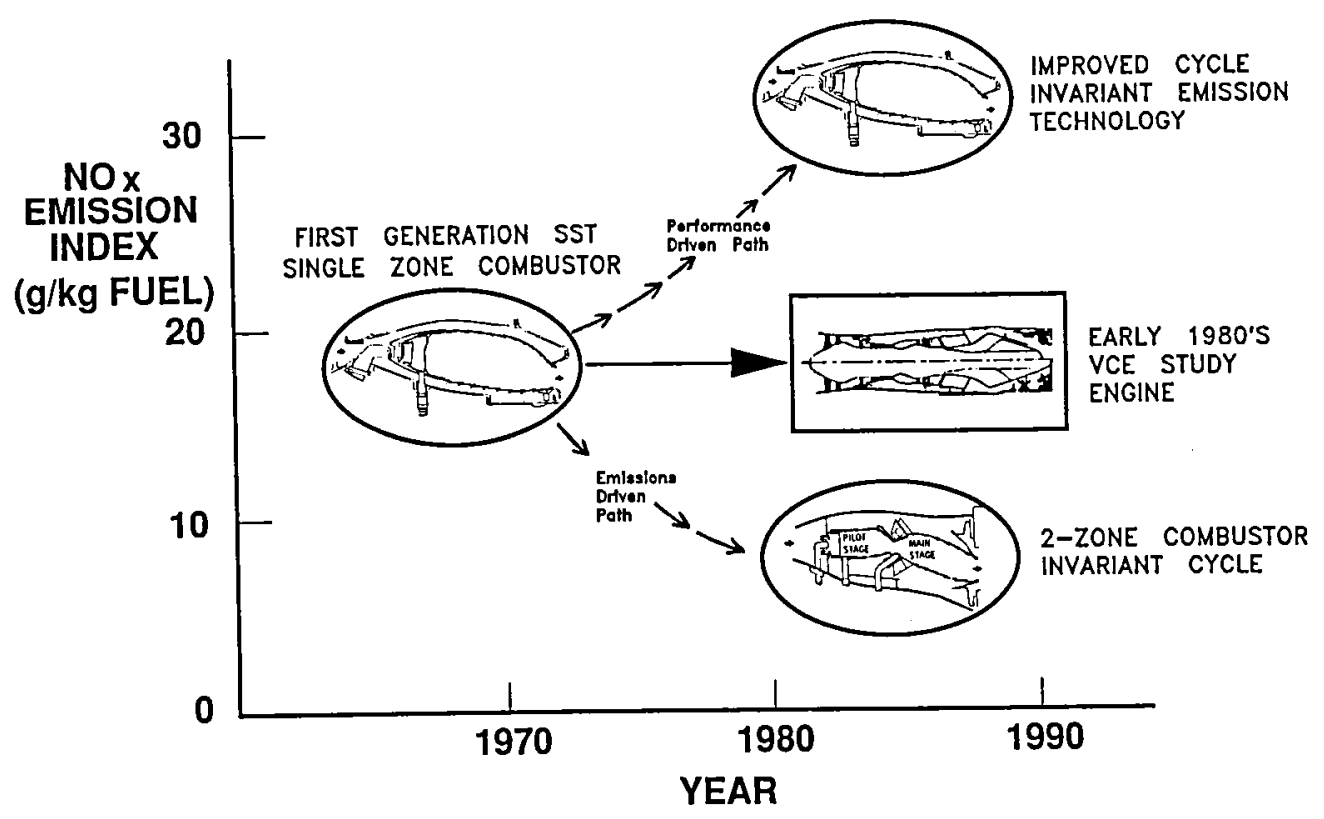

Fig. 19 History of SST cruise $\mathrm{NO}_{\mathrm{x}}$ emission reduction. 


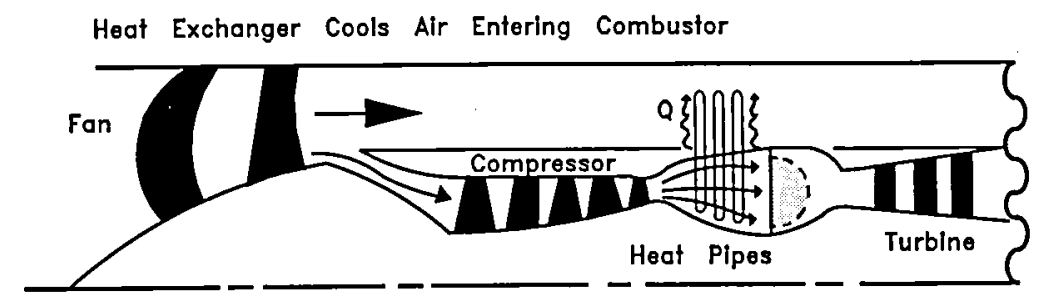

- REDUCES NO $X$ BY 4 X FOR 3\% TSFC PENALTY - WEIGHT AND COMPLEXITY PENALTIES

Fig. 20 Combustor pre-cooling approach to reducing $\mathrm{NO}_{\mathrm{X}}$.

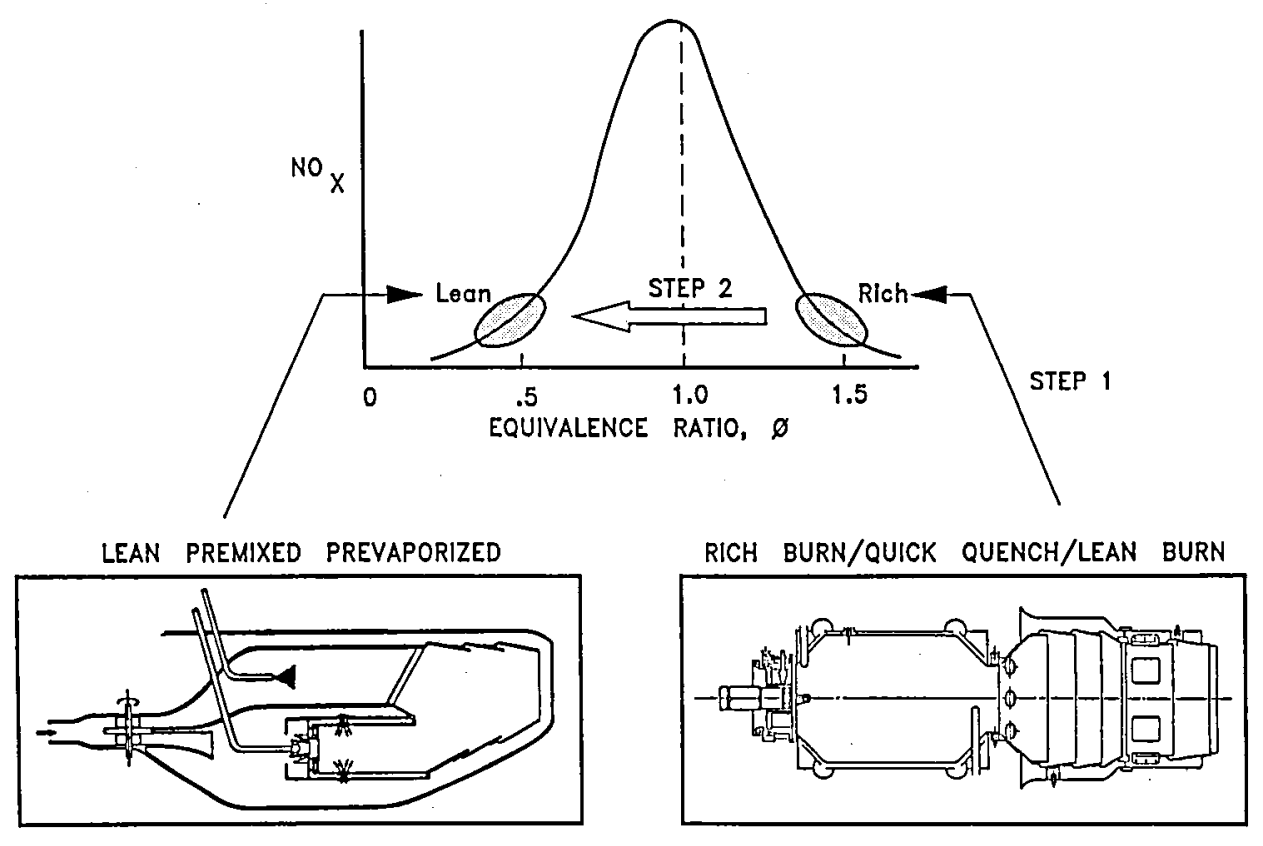

Fig. 21 Variation of $\mathrm{NO}_{\mathrm{X}}$ with equivalence ratio. 


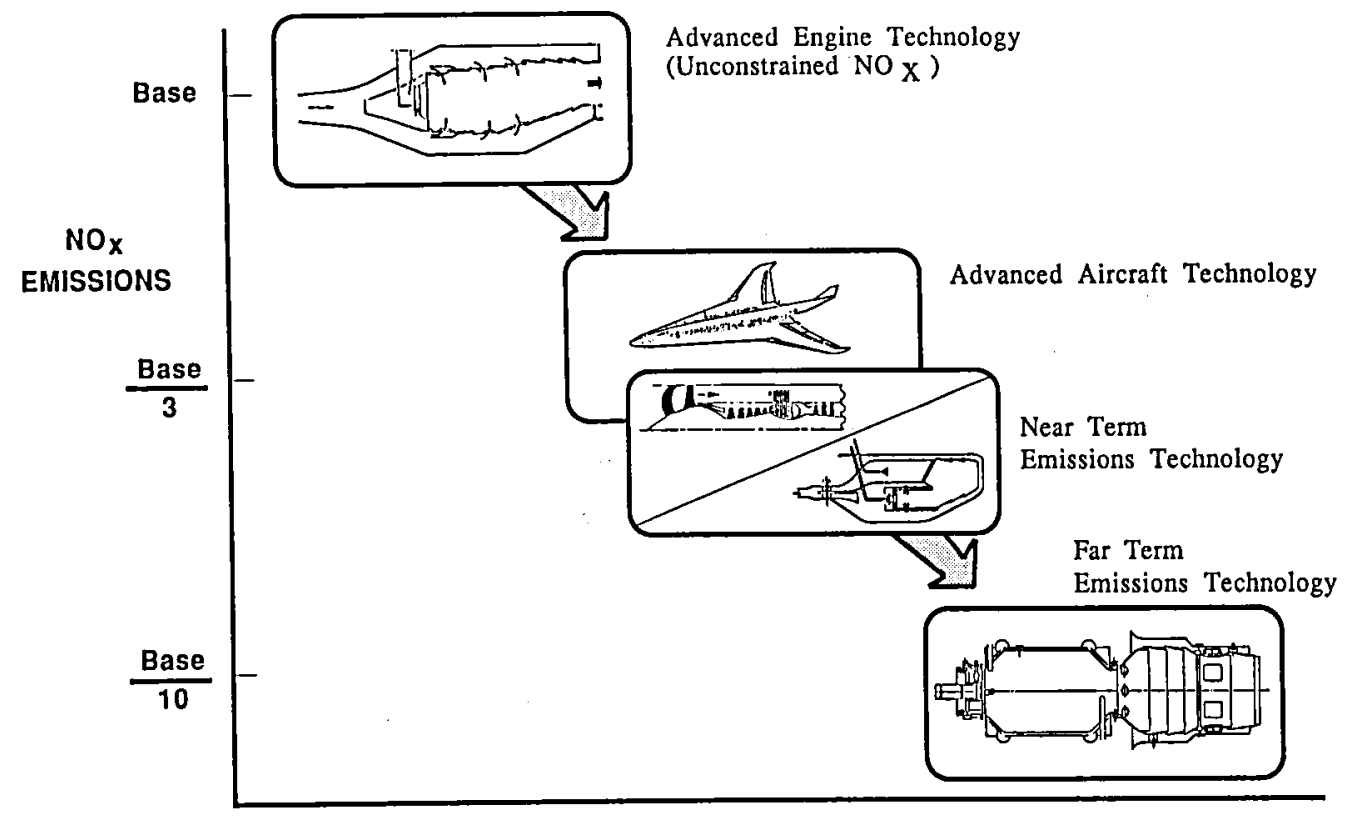

Fig. 22 Emissions technology impact.

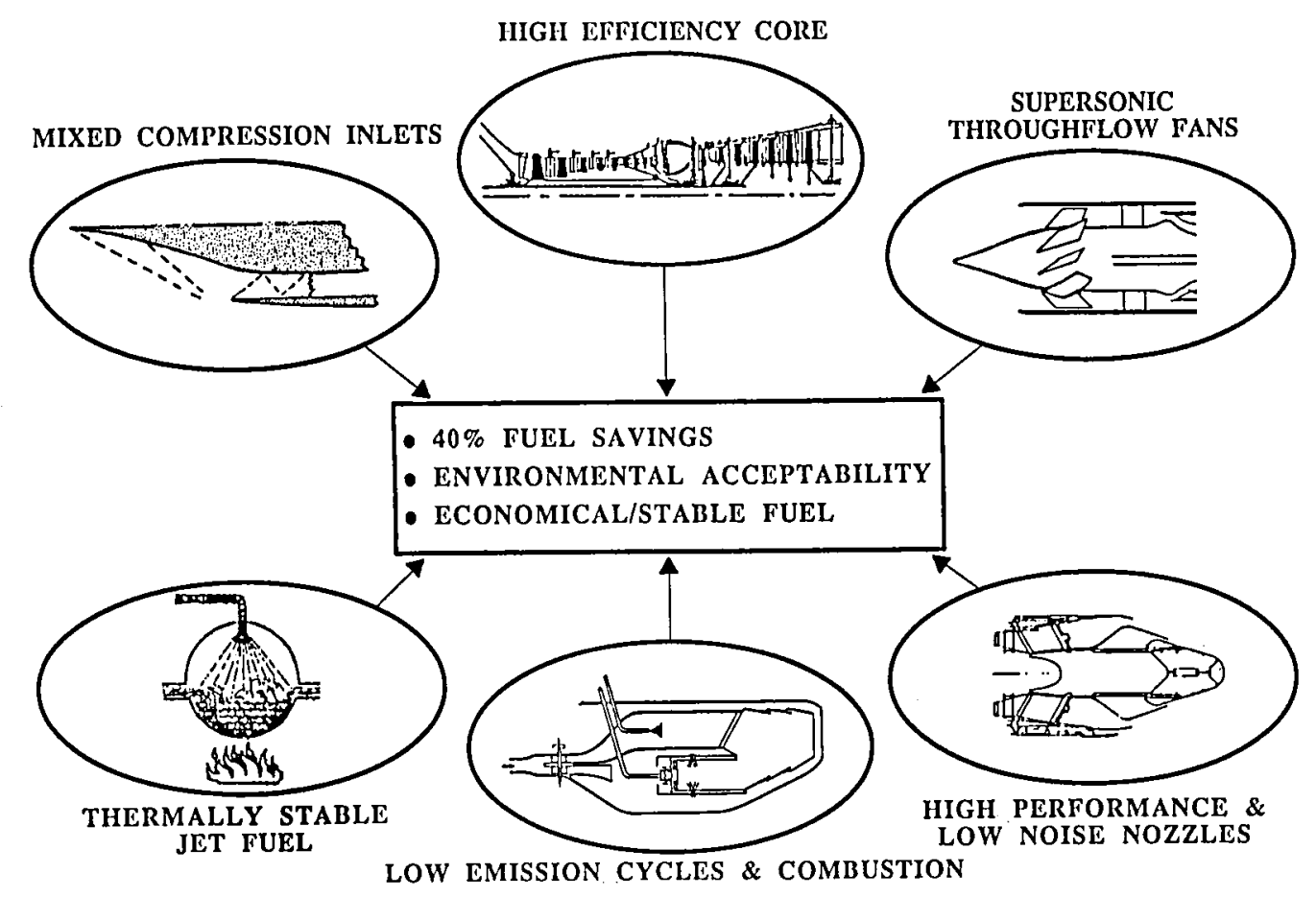

Fig. 23 High-speed propulsion technologies. 


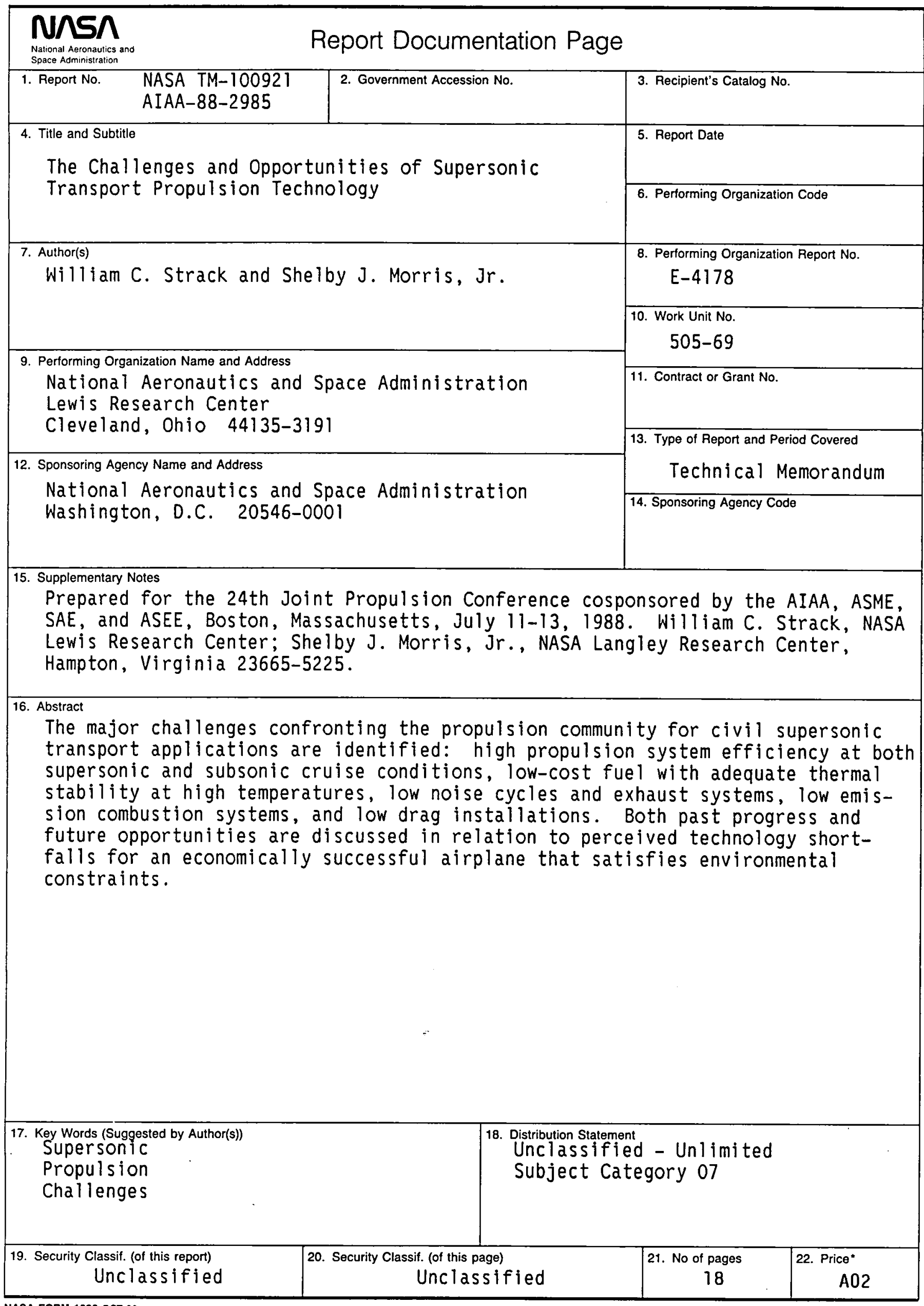


National Aeronautics and Space Administration

Lewis Research Center

Cleveland, Ohio 44135

Official Business

Penalty for Private Use $\$ 300$

\section{ADDRESS CORRECTION REQUESTED}

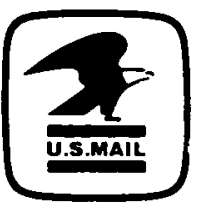

Postage and Fees Pard National Aeronautics and

Space Administration

NASA. 451 